\title{
Double-Loop Learning and the Global Business Student
}

\author{
Ina Freeman \\ Jones International University \\ Peter Knight \\ University of Wisconsin Parkside
}

\begin{abstract}
In preparing students for employment in commerce, the student needs to be aware of many aspects not necessarily included in business programs. In recognizing students often have no or limited exposure to foreign environments, the authors developed an electronic exchange between students in Canada and Kazakhstan. In this exchange, students not only learned about foreign marketplaces but were able to integrate classroom teachings and text knowledge into their actions. This approach resulted in enhanced learning for students through double-loop processes and development in their other courses.
\end{abstract}

\section{RÉSUMÉ}

Dans la préparation des étudiants pour un emploi dans le commerce aujourd'hui, l'étudiant doit connaître de nombreux aspects aucune nécessairement inclus dans les programmes d'affaires. En reconnaissant les étudiants ont souvent l'exposition on pas limité à environnements étrangers, les auteurs ont élaboré un échange électronique entre les élèves en Canada et aux Kazakhstan. Dans l'échange, les étudiants ont non seulement appris au sujet des marchés étrangers, mais ont été en mesure d'intégrer les enseignements en classe et l'information dans leurs textes dans leurs actions. Il en a résulté dans l'apprentissage renforcé par double boucle des processus et de développement dans leurs autres cours. 
In today's business environment, students require a global awareness not only of intended marketplaces but also of events and changes in the global landscape that will affect them and the world of commerce. Optimally, this knowledge develops through double-loop learning, achieved through knowledge of global events and understanding of different cultures. Ideally, students begin to interpret and understand these events and cultures through questioning their own their personal Self-Reference Criterion and Ethnocentrism (Pun, Lewis, \& Chin, 2003; Cateora, Gilly, \& Graham, 2009). Further, students learn to collaborate effectively with those from other cultures. In short, students prepared to engage in double-loop learning are more likely to be leaders in the future global business economy.

We initiated an international marketing assignment that involved one-onone communication between students in two countries. This assignment quickly demonstrated learnings not originally contemplated. We hypothesize that by using a greater number and variety of applications of double-loop learning theory, business students are exposed to increased effectiveness in working across cultures that have different "theories-in-use." Further, by using double-loop learning strategies, students will be better able to engage in open reflection of their own espoused and in-use theoretical perspectives.

To demonstrate this claim, we discuss an assignment wherein double-loop learning facilitated students' intercultural understanding and dichotomies between espoused theories and theories in use in two countries. This assignment demonstrates how double-loop learning experiences better equip students to become lifelong learners in the global business world, giving them (and Canadian business schools) a competitive advantage. In response to Czinkota (2006), who notes universities have not "kept pace with globalization and the transformation of world relations" (p. 153), the authors conclude that Canadian business schools might consider structuring and better promoting intercultural learning experiences such as international exchange programs (both student and professorial exchanges) and global distance education that promotes personal contact using information and communication technologies (ICT) to foster or enhance doubleloop learning.

\section{INTRODUCTION}

Double-loop learning was first discussed in academic literature by Argyris and Schön $(1974,1978)$ as a one part of learning theory that distinguished between single-loop and double-loop learning. In single-loop learning, entities (individuals, groups, or organizations) modify their actions according to the difference between expected and obtained outcomes without considering the reasons underlying the actions. In double-loop learning, the entities question the reasons, including the values, assumptions, and policies that led to the actions in the first place. If they review those reasons to improve the outcome or processes, then second-order or double-loop learning occurs. Double-loop learning differs from single-loop learn- 
ing by invoking questions and seeking solutions to improve decisions and actions stemming from single-loop learning (Argyris \& Schön 1978). Further, double-loop learning facilitates the integration of knowledge into actions that result in exploring new learning opportunities. Thus, learning occurs twice: once as the result of one's experience and again on the examination of the underlying premise, action, or theory on which the experience is founded.

In terms of global marketing, two of the primary underlying premises, theories, or actions that should be examined are one's Self-Reference Criterion (SRC) and ethnocentrism derived from the experiences of growing up in one's national and/or regional culture (Pun et al., 2003; Cateora et al., 2009). SRC refers to an unconscious reference to one's cultural values, experiences, and knowledge as a basis for decisions (Bond, 1994; Schwartz, 1994) because of their perceived "truth" (Purcell, 1998). Cited as a major impediment to effective cross-cultural and international collaboration (Bailey, Chen, and Dou, 1997; Heslin, 2005), SRC must be understood within international business. If not adequately reflected upon and examined, SCR can result a number of outcomes: failing to recognize the need to take action, discounting the cultural differences that exist among countries, and reacting to a situation in a manner offensive to your hosts. Ethnocentrism notes the superiority of one's culture or company and can be an impediment to crosscultural business collaboration (Pun et al., 2003; Cateora et al., 2009).

Double-loop learning, which addresses SRC and ethnocentrism, would be expected within business schools as these institutions are the training grounds and identity developers for individuals anticipating commerce as their workplace (Petrigliere \& Petrigliere, 2010). But training including the differences of cultural norms and behaviours present in global business requires individuals to rethink previously held assumptions and the resulting actions based on one's SRC (Tran \& Dawson, 2008), ideally resulting in the implementation of double-loop learning. The ability of parties to engage in double-loop learning has been demonstrated to lead to cross-cultural collaborations that are more productive and enduring (Tsang, 2002). Thus, double-loop learning enhances the problem-solving capabilities of all collaboration parties (Tsang, 2002), providing a sustainable competitive advantage that is hard to replicate due to the idiosyncratic knowledge and methods created by the synthesis of two or more different approaches seeded in differing cultural values.

Behaviours associated with double-loop learning, such as questioning results and exploring alternatives, are often cited as being observed in a particular marketing segment niche: the young cosmopolitans or YoCos. The American Marketing Association (2006) and marketing firms (LaPlaca Cohen, 2006) identify this segment as rooted in ideologies of globalism and heterogeneity. People in this segment perceive the value of and seek exposure to the diversity offered by a wide variety of national cultures in their day-to-day lives, without or with minimal use of the restrictive lens of their SRC. They seek new knowledge and thrive on the exploration of others around the globe: they are exposed to double-loop learn- 
ing. This orientation in turn shapes their own expressions of their identity and personal style in interactions with others (American Marketing Association, 2006). Most relevant to this paper, this segment often benefits from educational systems that encourage exploration outside the traditional expectations. Bird and Stevens (2003) suggest that the business leaders of tomorrow will possess many of the characteristics, skills, and orientations of YoCos in being "globals" who can freely navigate and operate in a variety of international and cross-cultural environments. This potential outcome requires universities to step up and train students to fulfill these roles.

In this paper, we discuss the benefits and competitive advantages that business students exposed to double-loop learning, particularly through international collegiate collaborations, can accrue in preparing for tomorrow.

\section{LITERATURE REVIEW}

\section{Double-Loop and Other "Disruptive or Generative" Learning Theories}

An individual's tacit mental maps provide guidance in situations, including planning, implementing, carrying out, and reviewing actions. Using mental maps, learning is based on complying with previously established norms, the applied action strategy, and the realized outcome. The result of this single-loop or "adaptive" learning is incremental change. This type of learning solves problems but ignores the question of why the problem arose in the first place.

Alternatively, double-loop or generative learning focuses on transformational change in the status quo. Double-loop learning is generative learning because it uses feedback from past actions to question assumptions underlying current views, methodologies, and outcomes such as one's SRC or ethnocentrism. When considering feedback, managers and professionals need to ask not only the reasons for their current actions but also what to do next and, even more importantly, why actions based on an alternative paradigm are not implemented (Argyris \& Schön, 1978).

Figure 1.

Double and Single-Loop Learning

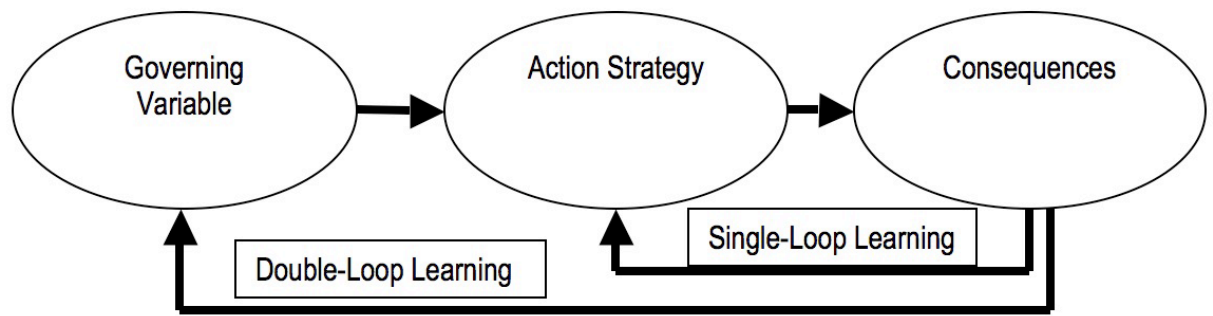


As noted in Figure 1, single-loop learning allows the consequences of actions to influence future action strategies, whereas double-loop learning demands review of the basis or governing principles on which the action strategies are formulated. This return to the underlying root beliefs or governing variables to determine future actions differentiates double-loop from single-loop learning. For example, when looking at the process of education in post-secondary institutions, one can see single-loop learning used extensively in courses using a "traditional" learning environment. Students sit in class and absorb information that is then regurgitated during examinations. Double-loop learning occurs when students are challenged to examine and apply the information via case studies, discussion, debate, or other reflective exercises. Students use the original theories and are asked to apply them in a real-life situation. After the students' reflection, the exercise may change their understanding of the theory or underlying variables such as SRC and ethnocentrism. When classes examine problems from a cross-cultural perspective, this approach enables students to compare and contrast the dominant culture to other cultures and cultural perspectives.

Double-loop learning links to the concept of theory-in-use (Argyris \& Schön, 1978) by examining the existing gap between what individuals say (espoused theory) and what they actually do (theory-in-use). Behaviour is most frequently consistent with mental models (theory-in-use) and not in accordance with espoused theory. An example can be noted when top management issues orders, memos, and directives, which alone are insufficient to change employees' behaviours. In the case of ethnocentrism and SRC, it may be "politically correct" to espouse one theory while remaining firmly rooted in SRC or ethnocentrism without fully realizing it.

Facilitating the understanding of new situations requires the alignment of espoused theories with theories-in-use. When people are dealing with change, double-loop learning techniques help an organization's members understand the reasons for the change and thus to contribute to it. This development enhances effective organizational change because of convergence between the espoused theory and the theory-in-use. This paper argues that double-loop methods of instruction better prepare students for the inevitable contradictions between the expected results stemming from their espoused theory and the differing consequences stemming from the implemented theories-in-use. These contradictions will be particularly evident in interactions with cultures having different theories-in-use based on their SRC and ethnocentrism, presenting unique challenges for management and students.

Both single-loop and double-loop learning require changes in action strategies, but single-loop learning does so without revision of the underlying principles. This change in strategies creates the impression that organizations change and thus can be depicted as organizational learning systems. But in reality the change in strategies stems from the implementation of revisions in strategies, not the true learning that double-loop learning would facilitate (Argyris, 1982). Singleloop learning does have feedback loops that inhibit error detection and correction 
because the self-reinforcing behaviour based in common organizational assumptions results in an atmosphere of mistrust, defensiveness (Edmondson \& Moingeon, 1999), stagnation, and failure.

When old procedures will clearly fail, double-loop learning mandates a thorough examination of governing or underlying values, behaviours, and philosophies. Inferences are drawn by stakeholders who then form a consensus on the direction of future actions (Anderson, 1997). As such, a fundamental component of doubleloop learning is actionable knowledge (Paul, 2003) based on good quality, verifiable data through which actionable strategies can be implemented (Argyris, 1993). Strategies based on information and made explicit, tested, and retested with consistent findings produce a dialogical result (Argyris \& Schön, 1996). Double-loop learning ensures assumptions made and beliefs held are and continue to be optimal for the organization (Argyris \& Schön, 1996), recognizing in the case of global business the impact of SRC and ethnocentrism. In short, the foundation of double-loop learning comprises valid information, informed choice, and vigilant monitoring both during and following the implementation of error detection and correction (Argyris, 2002) that involve creativity and reflexivity in considering the outcome.

The basis in actionable knowledge and strategies found in double-loop learning becomes crucial when considering academic work and its usability to the future practitioner. The results, including insights, intuition, and "hunches" (Nonaka, 1996), occur in a learning environment in which errors and fallacies are openly confronted regardless of potential embarrassment, threat, negative surprises (Argyris, 2002), or the discomfort of any or all of the parties. The encouragement of double-loop learning demands openness in the learning environment.

Senge (1990) discusses different kinds of learning, including adaptive learning that entails coping and simply manoeuvring within the existing framework, and generative learning that requires a global view of the systems and the organizations operating with these systems. Adaptive learning can easily be included within single-loop learning, but generative learning requires a more inclusive view that, if taken as we interpret Senge (1990), mandates an examination of the underlying basis of decisions. Generative or double-loop learning results in a new perspective of the situation, which in turn results in a new solution. The implementation of the new solution may promote further questioning as the process progresses, thus creating a constant evolution or the potential for evolution of the process and the results. Within an international or global environment, the importance of this ability to evolve cannot be underestimated.

\section{Culture and Conceptual Change in Organizations}

In international business, the need to understand the partner, buyer, or vendor who comes from another country is highlighted. Regardless of which borders are crossed, cultural boundaries will be crossed. As a result, those in business who deal across international boundaries need to be aware of cultural differences to be 
successful. This awareness includes cognition of the impact of the SRC and ethnocentrism of both the head office and the international location.

Numerous academics research and discuss national culture, including Hofstede (1980), Kogut and Singh (1988), and Schwartz (1994). We adopt and utilize the typology of Hofstede (1980), who discusses the difficulties of cross-cultural collaborations (Mitra \& Golder, 2002) using an anthropological approach that respects naturally occurring differences and may lead to conceptual changes for all parties in the collaboration. Hofstede divides these differences into individualism, powerdistance, uncertainty avoidance, masculinity, and long-term orientation. The interpretation of each of these partially depends on the country in which one grew up as well as where one may now be living. Hofstede (1980) recognizes these tendencies remain largely unconscious, complicating cross-cultural communication and interactions, such as learning about other cultures. Bird and Stevens (2003) suggest that individuals who successfully cross national borders and cultures are essential for business due to the increasing numbers of collaborative and joint ventures.

In business, organizations encompass national cultures that interact with the national culture (Alvesson, 2002) in accordance with social norms and expectations (Kunda, 1992). However, both organizational cultures and national cultures evolve and change (Williams, 1980). With increasing international contacts in business, the culture of business increases in complexity, a factor that business schools must prepare students to face. Educational institutions are the primary agencies that transmit the culture of the country to those entering the field of business, and they must remain current with both business and national culture.

\section{Double-Loop or Generative Learning and the Global Competitiveness of Organizations}

The ability to understand learning within, between, and among organizations, particularly those domiciled in different countries with different cultures, increases in importance with the rapid globalization of competition (Easterby-Smith, Crossan, \& Nicolini, 2000; Levinson \& Asahi, 1995). The ability of organizations to learn from partner organizations in different cultural environments results in the development of distinctive and enduring competitive advantages for organizations (Ring \& Van de Ven, 1994). This learning must be more effective than competitors', whether or not embedded in partner countries, to maintain a competitive edge (Ring \& Van de Ven, 1994). Double-loop learning processes afford the opportunity for individuals and organizations to create idiosyncratic and superior methods and processes that create distinct and enduring competitive advantages (Tsang, 2002).

The learning that promotes advantages in both mono- and multicultural environments, including inter-organizational learning, ultimately originates from "human heads" (Simon, 1991). The relationship between the ability of organizational actors and organizations to effectively learn how to learn has often been discussed in the literature. Crossan, Lane, and White (1999) provide one of the most oftcited and comprehensive typologies regarding how organizational learning, and 
thus renewal, ultimately occurs through the process of individual learning. They suggest the ability of organizations to learn, renew, and maintain competitive advantage ultimately begins through individual processes of intuiting (experiences, images, and metaphors) and interpreting (common language and ontology's development of cognitive maps and dialogue). Shared understanding, mutual adjustments, and interactive systems facilitating integration of processes transform individual learning to group learning and renewal. These group-learning processes ultimately manifest into organizational learning, institutionalized through development of routines, diagnostic systems, rules, and procedures.

Therefore, through the organization's members who engage in double-loop learning, inter-organizational collaborations with firms based in other cultures create unique competitive advantages through generative learning processes. This cross-cultural, inter-organizational learning requires significant critical reflection on espoused and in-use theories, based on the SRC and ethnocentrism of individuals within the organization (Tsang, 1999). Reflection often results in learning for learning's sake (Mitra \& Golder, 2002; Tsang, 2002), which when first engaging in international inter-organizational alliances has strategic merit in gaining global market experience, even without definitive revenue and growth objectives. More often, though, successful inter-organizational alliances and other ventures requiring cross-cultural collaboration require substantial tolerance for and ability to manage high levels of conflict as both parties have specific and measurable objectives (Lei, Slocum, \& Pitt, 1997; Tsang, 1999). The willingness of the parties to work through conflict to discover and learn how to achieve positive outcomes originates from the strategic importance of the collaboration for each party (Cohen \& Levinthal, 1990; Tsang, 1999).

Historically, North American companies do not learn as effectively as Asian firms in these types of collaborations (Inkpen, 1998); that is, they have less absorptive capacity. The extent of cultural distance between the two parties, whether by now oft-cited measures (Hofstede, 1980) or other metrics (Schwartz, 1994; Kogut \& Singh, 1988), also suggests the inability of organizations to withstand inherent conflict and engage in productive cross-cultural collaborations (Mitra \& Golder, 2002). The presence within each of the collaborating organizations of key individu $\neg$ als who are adept at learning how to learn despite conflict between espoused and in-use theories of marketing is essential to developing productive cross-cultural collaborations. Normative marketing theory accommodates the turbulence within commerce and within political relationships; a critical element to the success of these collaborations (Crossan et al., 1999). In fact, Parkhe (1998) suggests that conflict occurs and must be managed by individuals involved in cross-national collaborations at five distinct levels: societal culture, national context, corporate culture, strategic direction, and management practices and organization. Incorporating these levels into international marketing where the determination of the environment is by its systems properties (Wilkinson \& Young, 2005) adds to the complexity of cross-cultural collaborations. 
The ability of Canadian organizations to effectively learn from organizations located in other nations and cultures must start with the learning capabilities of their employees and executives. These capabilities include the desire for lifelong learning that optimally originates from higher education (Cleveland-Innes \& Emes, 2005), specifically for executives or leaders of tomorrow. Bird and Stevens (2003) suggest that many of these leaders will be "globals," sharing the same mindset and orientation as the YoCo segment described earlier. For globals, their leading characteristic is learning to learn effectively, through either double-loop or other disruptive or generative learning models. Within the multicultural environment of Canada, YoCos and globals freely navigate and operate in a variety of national and ethnic cultures while being comfortable and experienced with generative or disruptive learning processes.

Becoming a global is an important ability to cultivate among business students. This ability requires students be engaged in education not only as a means to a job but also as a means to learn how to learn, explore the environment, and problem solve. Unfortunately, as a study of students at Canadian universities indicated, many participants were enrolled to earn a degree as a means to a better standard of living rather than as a means to acquire knowledge (Brotheridge \& Lee, 2005). Being interested only in attaining the degree reduces students' desire to learn or to become globally aware.

\section{Cross-Cultural Learning in Institutions of Higher Education}

Many undergraduate university students experience difficulty understanding the concept of generative learning because, at least in the first two years of most programs, students are tasked with learning relevant facts, theories, and documented evidence by rote (Starkey \& Tempest, 2009). Thus, this level incorporates single-loop learning as the student does not question the material and may simply commit it to memory, without questioning the underlying assumptions. Some higher-level undergraduates and graduate students may utilize the double-loop learning model to examine the actions necessary to achieve success in the course, the appropriateness of the likely results of the actions, the meaning of the grade together with its accuracy in reflecting the learning, and whether or not the grade's value encompass significant behavioural objectives. Senior or more advanced courses incorporate double-loop learning necessary in the field to continuously improve performance where learning involves creativity in using tried and tested tools (Starkey \& Tempest, 2009). In the context of professional courses, such as business that incorporates the notion of the "reflective practice" (Ewell, 1997), students critically reflect on the results of their actions, comparing them to what they have learned, thereby exploring adjustments to their future actions and learning strategies.

One venue for double-loop learning to enhance the likelihood of students adopting the skills of globals occurs through exposure to other cultures and ethnici- 
ties in an academic setting. While exposure to other cultures and ethnicities may not result in cross-cultural learning, exposure does provide one means through which students can expand their horizons. Cross-cultural learning can be guided by the components of culture as identified by Hofstede (1980), who suggests culture reciprocally creates and is created by one's environment and subsequently influences behaviour, thoughts, and actions. To be effective globals, students must understand the theoretical underpinnings of the consequences of cultural differences.

In terms of the ability of educational institutions to adapt to a changing global landscape, the Dearing Report mandates the key skills for graduating students as communication, numeracy, the ability to use information technology, and learning how to learn (National Committee of Inquiry into Higher Education, 1997, para. 9.17). These skills facilitate the employability of graduates who need to be able to immediately integrate into the working environment, as evidenced in the CNN interview with Jason Ferrara from CareerBuilder.com. Ferrara states that companies no longer have time to train. They are instead looking for talent who understand the job and immediately produce positive results (Sooey, 2010). This requirement creates stresses for educational institutions that traditionally inform today's practices based on research that can take a year or more to come to press, academic theories that were developed and remain unchallenged in a working environment that changes with the turn of world events, and academicians who either have never practised or have not practised for a considerable length of time. These challenges suggest the need to implement double-loop learning within higher educational institutions (Yorke, 2000). Others recognize the resistance of institutions and organizations to change, especially change that necessitates an examination of their foundations (Moore, Fowler, \& Watson, 2007).

Because many institutions resist the change that may result from double-loop learning (Moore et al., 2007), its efficacy remains primarily hypothetical. Bransford, Brown, and Cocking (1999) argue that active learners who have engaged in double-loop learning can better transfer their existing knowledge to new situations. This result may stem from active learners' need to apply theories and principles, thus recognizing the utility of the theories and principles so that students become confident in the applicability of their knowledge in different contexts (Magolda, 1999). While foundational knowledge must be there, double-loop learning enables students to utilize it to create innovative and unique solutions. These solutions can only be found by students who are capable of critical analysis using creativity and big-picture, out-of-the-box thinking to develop new meanings and new patterns (Pink, 2005). The importance of double-loop learning in schools of commerce stems from the increasing globalization that demands crossing geo-socio-cultural boundaries (Council of Graduate Schools, 2007).

To enhance the ability of students to become globals through opportunities for cross-cultural learning in higher education, the Report of the Committee on International Education (Colorado Commission on Higher Education, 1994) recommends the development of consortial arrangements, increased emphasis on and funding 
of international education, easing of transfer credits for students to enhance international exchange programs, and increased international education partnerships with the private sector (Colorado Commission on Higher Education, 1994). However, despite these recommendations, many institutions in both Canada and the United States fail to respond (Kennedy Manzo, 2005). This lack of responsiveness is particularly true in Canadian universities where opportunities to interact with exchange or visiting students from other countries rarely occur, particularly in terms of shared learning experiences with groups from countries with dissimilar cultures and within graduate-level education (Chen, 2006). In fact, in Canada only one university reports a full consortial arrangement (Freeman \& Knight, 2004), though many others report exchange programs. Less than one percent of Canadian university graduates experience an international exchange, with only about one dollar per capita spent on international exchange programs (Association of Universities and Colleges of Canada, 2003).

Reasons for the lack of exchanges include the limited cash reserves of universities and the inability of students to take the required time away from their employment. Despite common perceptions, not all intercultural learning experiences require large expenditures of cash or travel. With the increasing ease of access to computers and various computer programs that allow for international communication, computers provide one means of facilitating intercultural learning experiences for a relatively small cash outlay. The use of online conversations as a learning tool promotes "deeper learning" (Campos, Laferrière, \& Lapointe, 2005). The intercultural learning experiences gained by the use of the Internet expose students to other ways of thinking as well as challenging their perceptions and understandings about the world around them.

Although the curriculum incorporating the globalization of business presents in today's business schools. the inadequacy of the curriculum given the evolution of business today results in ill-prepared students (Selen, 2001). Institutions fail to utilize double-loop learning not only in teaching but also in the institution's management (Selen, 2001; Argyris, 1976). To better facilitate the implementation of double-loop learning, universities might consider exposing students to relevant experiential opportunities. For example, organizations looking to expand operations to new markets contemplate a steep learning curve when deciding on standardization or differentiation of the product and marketing. The success of the organization depends on the reflective or double-loop learning of the individuals concerning the new environment, the inherent risks and costs, and the entry methods. With rapid adoption of e-commerce, business leaders of tomorrow must also reflect on the blurring of national boundaries and borders (Cudmore, 2005).

\section{One Example of Double-Loop Learning in Post-Secondary Education}

Given the increasing need for students to recognize the globalization of commerce, we developed a class project that examined the preparation of students 
for this environment in two countries: Kazakhstan and Canada. Although the original intent of this study highlighted international business, it centres on the double-loop learning of the students. The similarities of the countries, including considerable reliance on primary goods such as agricultural products, oil, and gas, an emerging information and communications technology (ICT) industry, the existence of some manufacturing, and proximity to countries active in the political arena (the United States and Russia), facilitated the development of the project. Kazakhstan is an emerging country best known internationally for the oil reserves and the Russian space-launch in the steppes. Canada is a member of the G-8 association with a well-established and diversified economy.

Undergraduates constituted the sample population of the study, including students who would soon enter the business world. The 36 Kazakh students participated in a business-to-business marketing course and were primarily born in Kazakhstan, though the group also included international students from Germany, Korea, and Russia. The 95 Canadian students enrolled in two courses, Marketing in the High-Tech Sector and Basic Marketing, with 70 percent of the students born in Canada. The remaining students were born in Europe, South America, and South Asia, and were pursuing different majors (predominantly Information Technology, Economics, and Industrial Design). Some students in both countries had travelled extensively. However, many of the Kazakh students continued to travel as their parents had under the USSR, focusing on other Commonwealth of Independent States (CIS) countries and Russia. The students' nationality by birth and the places travelled are included in Tables 1 and 2.

Table 1

Students by Country of Birth

\begin{tabular}{llccc}
\hline Country of Birth & & Frequency & Percent & Cumulative Percent \\
\hline Canadian School & Canada & 30 & 69.8 & 68.9 \\
& Bangladesh & 1 & 2.3 & 72.1 \\
& India & 1 & 2.3 & 74.4 \\
& China & 3 & 7.0 & 81.4 \\
& Taiwan & 1 & 2.3 & 83.7 \\
& Malaysia & 1 & 2.3 & 86.0 \\
& Chile & 2 & 4.7 & 90.7 \\
& Sri Lanka & 1 & 2.3 & 93.0 \\
& Bolivia & 1 & 2.3 & 95.3 \\
& Pakistan & 1 & 2.3 & 97.7 \\
& Kuwait & 1 & 2.3 & 100.0 \\
& Kazakhstan & 23 & 85.2 & 85.2 \\
& China & 1 & 3.7 & 88.9 \\
& Tajikistan & 1 & 3.7 & 92.6 \\
& Russia & 1 & 3.7 & 96.7 \\
& Turkmenistan & 1 & 3.7 & 100.0 \\
\hline
\end{tabular}


Table 2

Students by Foreign Countries Visited

\begin{tabular}{llrrr}
\hline Countries Visited & & Frequency & Percent & Cumulative Percent \\
\hline Canadian School & None & 3 & 7.0 & 7.0 \\
& $1-3$ & 24 & 55.8 & 62.8 \\
& $4-5$ & 12 & 27.9 & 90.7 \\
& $7-9$ & 2 & 4.7 & 95.3 \\
Kazakh School & 10 or more & 2 & 4.7 & 100.0 \\
& No answer & 1 & 3.7 & 3.7 \\
& $1-2$ & 4 & 14.8 & 18.5 \\
& $3-5$ & 12 & 44.4 & 63.0 \\
& $6-9$ & 7 & 25.9 & 88.0 \\
& 10 or more & 3 & 11.1 & 100.0 \\
\hline
\end{tabular}

The assignment necessitated the students exploring a new marketplace for a typical product from their home country. It also entailed deciding whether the product could successfully be marketed in the other country.

The assignment learning objectives included familiarizing the students with business as it operates in another culture: the marketing techniques and expectations, the decision-making necessities of "going global," and the development of interest in another culture. Because of the Kazakh students' need to be envisioned as proficient regardless of the reality of the statement, the instructors did not administer pre- and post-questionnaires, so the students could approach the assignment without needing to posture in front of their peers. Instead, the instructors monitored the process carefully, discussing the unfolding events with each other regularly and administering a post-assignment survey. The survey, primarily open-ended questions and given to the students to complete in class, evaluated student learning and achievement of the course goals.

The assignment concerned marketing a product familiar to the students in the other country. Both classes received instruction in normative marketing theory; incorporating the strategies and actions of marketers in international business. This theory suggests what marketers should do to achieve success in relationships as well in as competitive advantage and other aspects of traditional marketing such as the marketing mix. Normative marketing theory also looks to how these standard concepts and innovative ideas can be incorporated within commerce within individual firms and with individual corporate actions (Wilkinson \& Young, 2005). In recognizing not only the four Ps (Price, Promotion, Place and Product) but also the four Cs (cost, convenience, consumer, communication) of marketing, the students accessed the students in the other country through cross-cultural email exchange, gathering information on how products were imported and marketed. While import and export responsibilities are commonly carried out by professionals in target countries, the students needed to understand the marketplace to determine the suitability of the product to the marketplace. The students then looked to the intricacies of marketing the product, with the results being communicated in a report. 
This activity developed the knowledge required to succeed in global marketing. The students used ICT to interact, facilitating an electronic learning experience between Kazakhstan and Canada. They enhanced their appreciation of the need to understand new marketplaces through their electronic connection to peers in another country. Although the students learn the information required to enter new marketplaces, many of these needs are not anticipated or under-anticipated. For example, the Kazakh students underestimated the time required for a ship to travel to the United States, and the Canadian students misunderstood the effects of the bi-nodal income in Kazakhstan.

This study addressed the application of double-loop learning within commerce education, a field not well discussed in the academic literature. In referencing the academic literature, studies advocate double-loop learning, but few examine its application and none examine the application in two countries. Thus, this study is unique in identifying the viability of the application of double-loop learning within international commerce education. As indicated in the literature review, this learning better prepares the students for employment in an international environment than the tradition pedagogical methods currently employed.

Despite the multiplicity of ethnicities within the Canadian university, the Canadian and Kazakh students were equally surprised by the differences between the nations. When instructors examined the types of products the Kazakh students chose to export, they found that students relied on Russia as a purchaser, which was evident in transportation routes, distribution channels, and consumer preferences. When instructors examined the types of products the Canadian students chose to export, they found that the students assumed the market bore similarities to Canada. However, in the concluding discussion of this assignment, both Canadian and Kazakh students admitted shedding their preconceived ideas about other marketplaces. This discussion encouraged the students to be creative in their analysis of the potential of the marketplaces. That is, the Canadian and Kazakh students re-examined their ideas about the unconditional acceptance of their products and the ease of entering a foreign market with a product manufactured in their own country.

In identifying key learnings from this project, students commented on the need to go beyond the thinking required in multiple courses previously taken. This conclusion met with resistance from some Kazakh students who were hampered by the learned and deep-seated mistrust of western nations. Some students began to open their minds sufficiently to accept Canadian students' expressions of interest in Kazakhstan. This development facilitated explorations, though they sometimes remaining primarily single-loop. Other students did not look to this assignment as an exercise in commerce but rather as a way to present their country with the pride they felt. These students' learnings began as single-loop learning but quickly evolved into double-loop learning with the contact with Canadian students. Their learnings initiated a new curiosity about the world and the thinking outside the former Soviet Union boundaries. Although the Kazakh way of life and the limitations on their 
chosen products of kumis, schubat, and kourt initially disappointed, the Canadian students incited an interest in a country they not previously contemplated.

In the following semester (fall of the next academic year), many of the Kazakh students engaged in this assignment began to challenge and explore in their other courses. This change created both a stir among other instructors who had previously experienced these students as docile receptors of information and excitement among other students who wanted to experience this type of exercise. The failure of native Kazakh instructors to replicate the assignment as requested by the students highlights the excitement about learning to learn (double-loop learning) for the students and the instructors' discomfort in stepping outside the singleloop methodology whereby they taught in the same framework in which they had learned, hierarchical and unchallenged. Their ability to change, though as great as the students', failed to incorporate the double-loop learning processes outlined in Figure 1 and Table 3 because of the hierarchical structure of the traditional educational institution.

Table 3 details the process of double-loop learning for the students in each country. The key governing variables include those aspects of the students' experiences and culture that formulated the students' perceptions of the other country. Based on their SRC and ethnocentrism, the students from both nations envisioned business would be conducted as it was conducted in their own country. They did not expect to find differences. This expectation demonstrates that regardless of their having read texts informing of differences, the students' perceptions remained unchanged from the foundations of their theory-in-use.

The action strategies observed clearly indicated a difference in self-identification between the countries. The Kazakh students hesitantly took part in the assignment, fearing rejection by the Canadian students because of their country's recent emergence and former USSR status. The Canadian students held no preconceptions about the Kazakh students, leading to difficulties in communication because they did not understand Kazakh students' reticence. Both the Canadian and the Kazakh students were pushed to re-examine the key governing variables. This re-examination led to a breakdown of previously held beliefs and opening doors for further communication and opportunities for understanding between the two nations.

The students in both nations came to better understand the need for cultural sensitivity and information when looking at marketplaces. They became willing to re-examine their key governing variables and open to exploring alternative beliefs and actions.

\section{IMPLICATIONS FOR CANADIAN BUSINESS EDUCATORS}

The authors suggest business education consider adopting a teaching philosophy more attuned to the needs of the world of business (Jackson, 2010). This approach would include generic and specific tasks (Jackson, 2010) and also the ability to incorporate double-loop learning. One important task of our higher educational 


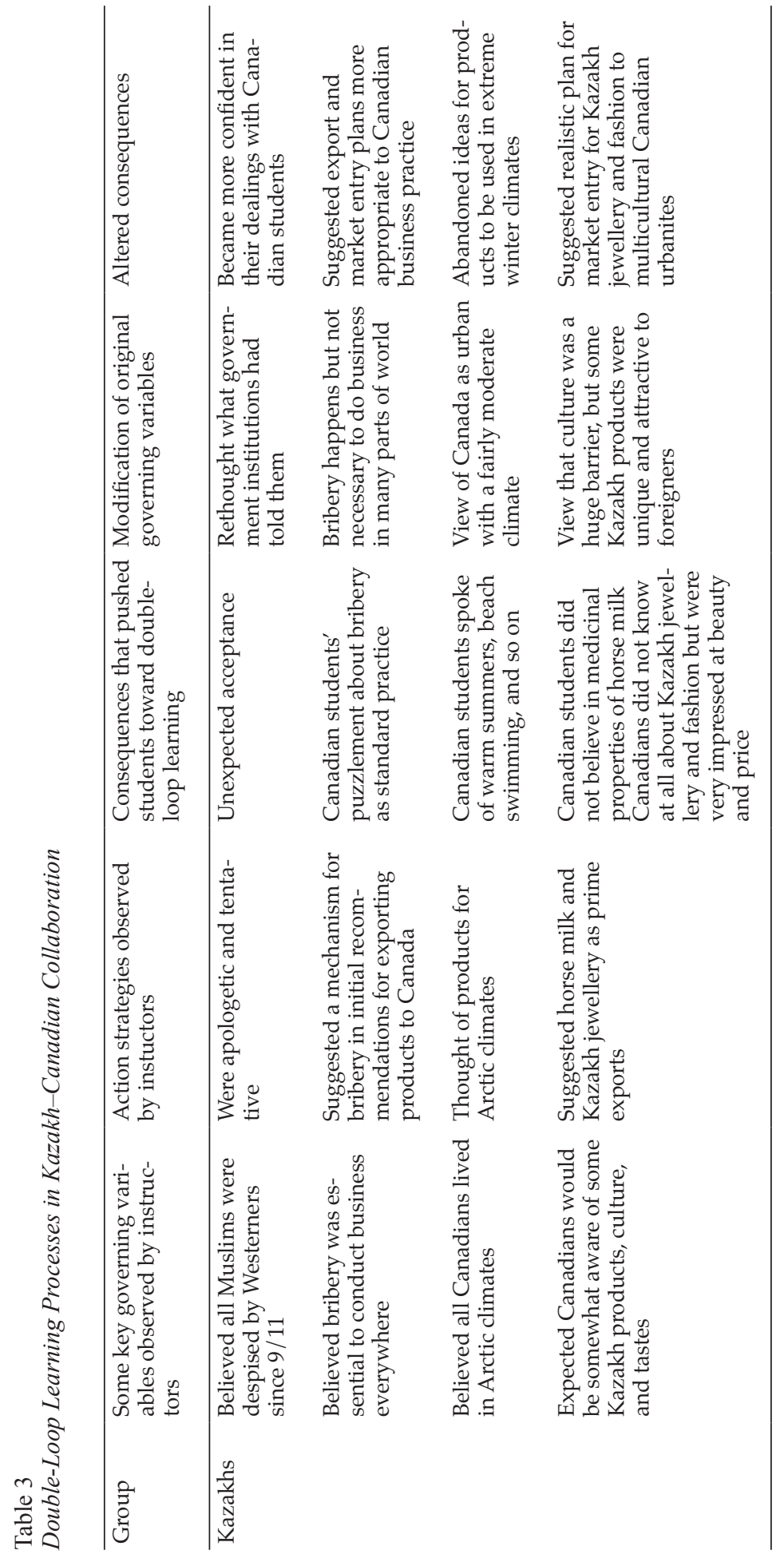




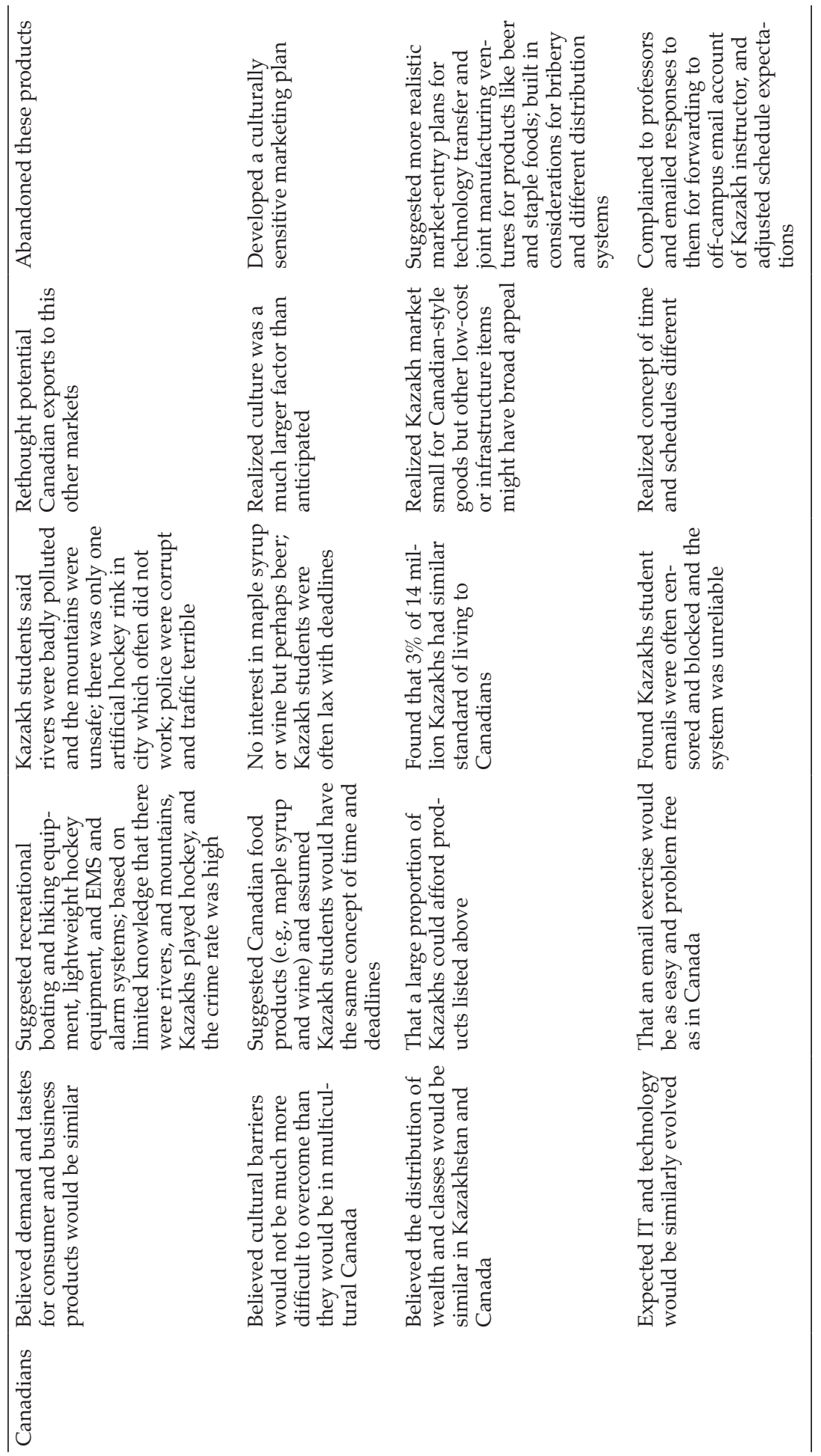


institutions is to develop globals, the business leaders of tomorrow (Bird \& Stevens, 2003), and incorporating double-loop learning does not mean abandoning learning the theories and principles underlying tertiary education. Indeed, it encourages the use of current examples and cases from the business world to enable students to apply theories and principles within simulated business practices. As well, the malleability of normative marketing theory facilitates double-loop learning.

For students to accomplish this kind of learning, academic faculty must be involved in the production of new knowledge that is both practically and theoretically sound. That is, university graduates critically analyze business situations, using double-loop learning to develop new insights and new solutions in light of both the existing knowledge and the potential of new knowledge, preparing students to enter a business environment that is evolving at an increasing pace. This evolution within business depends on the continual evolution of knowledge and the application of new knowledge for survival, expansion, and profitability.

Unfortunately, within the realm of business education, research and development of new knowledge into generative learning in undergraduate classroom settings presents as a "weak sister" in terms of publication benchmarks for tenure and advancing rank set by most Canadian business schools. Understandably, many business schools place high priority on production of research in the most reputable journals of the faculty member's area of specialization resulting in the greatest direct effect on the national and international rankings of business schools, one component used to attract faculty and funding. This research often challenges commonly adopted theories-in-use. Ideally, research of this nature is incorporated into in-class activities to encourage critical reflection. In many Canadian business schools, however, there is little formal incentive for research into classroom methodologies and learning theories. In fact, in many Canadian business schools, the professors teach similarly to the Kazakh professors, using the same methodology they were taught with rather than exploring new methodologies. By contrast, for example, the United Kingdom uses instructor training to ensure university professors' exposure to the theories and practical knowledge of how to teach. As indicated by the refusal of other Kazakh professors to adopt this style of assignment to encourage double-loop learning, the willingness of teachers to expand their methodologies may be lacking.

In examining learning in general on university campuses, Tagg (2007) found that, despite the proclivity of faculty to innovate in their research, expand their courses, and update course material, they have not changed their basic pedagogy style, which is teacher-directed and didactic (Knowles, 1984). For example, despite the adoption of the consumer's perspective in many courses, the majority of marketing texts retain the producer-relevant $4 \mathrm{Ps}$. This focus denies differences in culture and anthropological perspectives found in international marketing and business, as discovered by the students involved in this study. Historically, educators who are successful as a result of their skill in single-loop learning rarely challenge their governing values, explore their belief systems, or engage in double- 
loop learning and inquiry (Argyris, 1991). The reasons for not challenging their approach include that these educators may rarely fail (and thus never learn how to learn from failure), may be protective of their image (and thus appear to not need to change their learnings or teaching), and may work in university atmospheres that do not openly accept failure or admit that their professors err (Argyris, 1991). Thus the potential for failure precludes exercises such as the Canadian-Kazakh exchange and denies the students the opportunity to learn how to learn, as well as learn how to arrive at win-win solutions in international business.

In response to the increasing call from employers for accountability in education, business education institutions have adopted accreditation by the Association to Advance Collegiate Schools of Business (AACSB) as one of the tools to certify their educational process. This accreditation, already awarded to approximately 17 of 48 Canadian university business schools in May 2010 (AACSB, 2010), requires programs "to expose [their students] to cultural practices different than their own" and must "document how it achieves diverse viewpoints among its participants as a part of the students' learning experience" (AACSB, 2011, 12) AACSB thus mandates a global perspective, though not specifying how one might be achieved.

AACSB accreditation requires an annual inventory of faculty teaching, research, and service activities. The inventory includes a requirement for faculty to categorize research publications as being either "learning and pedagogical research," "discipline based scholarship," or "professional practice," with significant overall contribution to each category required to maintain AACSB status. The inclusion of learning and pedagogical research endorses research into pedagogy. As an increasing number of Canadian business schools attain AACSB status, this achievement assures, at least at an aggregate level, that Canadian business faculty will have an increasing responsibility to research and apply newer instruction methods that reflect the requirements of today's business environment. Within this responsibility, we suggest that greater understanding of and implementation of generative or double-loop learning opportunities are important areas of both research focus and classroom implementation to ensure greater relevance to and within undergraduate and graduate business programs. As AACSB reaches across nations, it may become increasingly easy to find professors in other countries to engage in similar cross-cultural international projects or to develop other unique projects that answer the need for students to both learn of business across borders and to expand their learning style to include double-loop learning, with exploration and innovation as a result.

At a minimum, the implementation of double-loop learning or second-order change in university curriculum and teaching, particularly at the advanced levels, will challenge students to expand their base knowledge into an overarching metaknowledge. Cardno (2007) states this "metaknowledge is the cornerstone of self-awareness and self-discipline that underpins the praxis of dilemma management—an approach that simultaneously engages head, heart and hand" (p. 33). 
Because universities function as the training ground for tomorrow's workers and leaders, the implementation of double-loop learning in foundational degrees will eliminate the defensive posturing and subsequent stagnation resulting from singleloop learning (Argyris, 1990). Double-loop learning will facilitate increasing globalization in commerce by facilitating students' exploration of and exposure to other cultures and ethnicities as well as differences in practices and thought. With normative marketing theory used in this curriculum, the application of double-loop learning quickly allows students to see differences and seek to understand their causality. The espoused normative marketing theory facilitates the growth of students in the international arena by accepting modifications on an ongoing basis in both the methods of marketing and the products. As demonstrated by the students in the exchange, once they engage in double-loop learning, the underlying premise to problems or solutions can be examined, shedding new light on the situation by using a new theory-in-action that coincides with the predominant espoused theory.

The Canadian and Kazakh students share discomfort in implementing doubleloop learning with others around the globe. We note a number of similarities attributable across ethnicities and nationalities. In working with double-loop learning, Argyris (1995) found "saving face" to be an increasingly global or universal rule, albeit the specific behaviours vary. The face-saving rules include bypassing or deflecting away from the topic and concealing the deflection, as evidenced in the exercise and addressed by the professors. Because the exercise was online, the professors monitored the students' responses, interfering with the hiding or concealment of deflection by addressing issues immediately. A similar platform appear elsewhere when firms adopt double-loop learning, such as an engineering firm in Singapore in the provision of an intersection for investigation, reflection, and knowledge sharing (Yeo, 2007). Documentation of double-loop learning originates, among others, in the European banking sector (Salmador \& Bueno, 2007), the American software industry (McAvoy \& Butler, 2007), the small and medium business sector (Williams, 2007), and the educational environment (Moore et al., 2007).

\section{CONCLUSION}

Within the educational environment, the desire to implement instruction that encourages and builds double-loop learning for instructors and students does not lend itself to the deprofessionalization of teachers, as was argued by the British press when the government of the United Kingdom established new initiatives (Harris, 1997; Hodkinson, 1997). Nor does it validate the fear that universities are becoming technical schools. Instead, double-loop learning enlarges the role of universities not only to impart knowledge to students but also to help students find new knowledge to further enrich their classes.

The difficulty in implementing double-loop learning originates in the resistance of organizations to change. Double-loop learning occurs only if the learner wants to learn. Moore et al. (2007) recommend decreasing the level of learning 
anxiety through the use of personal and professional development programs that promote double-loop learning. Argyris (1993) identifies four key assumptions that must be held for double-loop learning to be effectively implemented by leaders and thus by educators:

1. Learning is not simply a discovery or an insight but must be accompanied by the knowledge of how to implement the knowledge based on doubleloop reasoning.

2. Leading the learning necessitates the same competencies regardless of the audience or participants.

3. Theories of action have commonalities across many human beings.

4. Integrating theories-in-use and the reasoning behind these with managerial disciplines is an effective method of teaching leadership.

Thus, to enhance learning, teaching necessitates competent individuals, knowledgeable about the skills they teach and open to discussing the challenges encountered when using double-loop learning. This discussion will assist in the evaluation of the validity of new concepts and ideas. For optimal effectiveness, teaching should include practical application that is relevant to the environment into which the students will emerge upon graduation. In other words, educators teaching their students to investigate the causality will enhance the students' progression throughout their career. In this investigation, the students discover not only more about themselves but also more about the subject of the investigation and new ways of looking at that subject that will ultimately benefit themselves and others. Once students and faculty feel comfortable engaging in this questioning, they will be ready to begin triple-loop learning.

\section{REFERENCES}

Alvesson, M. (2002). Understanding organizational culture. London, UK: Sage.

American Marketing Association. (2004). Get to know the YoCo: Reaching today's U.S. urban youth. Retrieved from AMA website: https://amawebcasts.webex.com/ec06001/ eventcenter/recording/recordAction.do?theAction=poprecord\&confViewID $=335650279 \&$ rnd $=3276144655 \&$ siteurl=amawebcasts\&siteurl $=$ amawebcasts $\& U N=54 \&$ needFilter $=$ false

Anderson, L. (1997). Argyris and Schön's theory on congruence and learning. Retrieved from website: http://www.scu.edu.au/schools/sawd/arr/argyris.html

Argyris, C. (1976). Single-loop and double-loop models in research on decision making. Administrative Science Quarterly, 21(3), 363-375.

Argyris, C. (1982). Reasoning, learning, and action: Individual and organizational. San Francisco, CA: Jossey-Bass.

Argyris, C. (1990). Overcoming organizational defenses. Facilitating organizational learning. Boston MA: Allyn \& Bacon.

Argyris, C. (1991). Teaching smart people how to learn. Harvard Business Review, 69(3), 99-109. 
Argyris, C. (1993). Education for leading-learning. Organizational Dynamics, 21(3), 4-17.

Argyris, C. (1995). Action science and organizational learning. Journal of Managerial Psychology, 10(6), 20-26.

Argyris, C. (2002). Double-loop learning, teaching, and research. Academy of Management Learning \& Education, 1(2), 206-218.

Argyris, C., \& Schön, D. (1974). Theory in practice: Increasing professional effectiveness. San Francisco, CA: Jossey-Bass.

Argyris, C., \& Schön, D. (1978). Organizational learning: A theory of action perspective, Reading, MA: Addison Wesley.

Argyris, C. and Schön, D. (1996). Organizational learning II: Theory, method and practice. Reading, MA: Addison Wesley.

Association of Universities and Colleges of Canada (2003). Higher education and university research: Empowering Canadians and their communities. Retrieved from AUCC website: http://www.aucc.ca/_pdf/english/reports/2003/prebud_10_08_e.pdf

Association to Advance Collegiate Schools of Business. (2010). Schools accredited in business, ordering by country/region, state, name. Retrieved from AACSB website: https://www.aacsb.net/eweb/DynamicPage.aspx?Site=AACSB\&WebKey=00E50DA98BB0-4A32-B7F7-0A92E98DF5C6.

Association to Advance Collegiate Schools of Business. (2011). Eligibility procedures and accreditation standards for business accreditation. Retrieved from AACSB website: http://www.aacsb.edu/accreditation/standards-2011-revised-jan2011-final.pdf

Bailey, J. R., Chen, C.C., \& Dou, S.-G. (1997). Conceptions of self and performance-related feedback in the U.S., Japan, and China. Journal of International Business Studies, 28(3), 605-624.

Bird, A., \& Stevens, M. J. (2003). Towards an emergent global culture and the effects of globalization on obsolescing national cultures. Journal of International Management, 9(4), 395-407.

Bond, M. H. (1994). Into the heart of collectivism: A personal and scientific journey. In U. Kim, H. C. Triandis, C. Kagitcibasi, S.-C. Choi, \& G. Yoon (Eds.), Individualism and collectivism: Theory, method, and applications (pp. 66-76). Thousand Oaks, CA: Sage.

Bransford, J. K., Brown, A. L., \& Cocking, R. R. (1999). How people learn: Brain, mind, experience, and school. Washington, DC: National Academy Press.

Brotheridge, C. M., \& Lee, R. T. (2005). Correlates and consequences of degree purchasing among Canadian university students. Canadian Journal of Higher Education, 35(2), 71-97.

Campos, M. N., Laferrière, T., \& Lapointe, J. P. (2005). Analyzing arguments in networked conversations: The context of student teachers. Canadian Journal of Higher Education, 35(4), 55-84.

Cardno, C. (2007). Leadership learning-The praxis of dilemma management. ISE A, 35(2), 33-50. 
Cateora, P., Gilly, M., \& Graham J. (2009) International Marketing (14th ed.). New York, NY: McGraw-Hill.

Chen, L. H. (2006). Attracting East Asian students to Canadian graduate schools. Canadian Journal of Higher Education, 36(2), 77-105.

Cleveland-Innes, M., \& Emes, C. (2005). Principles of learner-centered curriculum: The call for change in higher education. Canadian Journal of Higher Education, 35(4), 85-110.

Colorado Commission on Higher Education. (1994). Report of the Committee on International Education. Denver, CO: Higher Education Clearing House.

Council of Graduate Schools. (2007). Graduate education: The backbone of American competitiveness and innovation. Washington, DC: Council of Graduate Schools.

Crossan, M. M., Lane, H. W., \& White, R. E. (1999). An organizational learning framework: From intuition to institution. Academy of Management Review, 24(3), 522-537.

Cudmore, G. (2005). Globalization, internationalization, and the recruitment of international students in higher education and in the Ontario Colleges of Applied Arts and Technology. Canadian Journal of Higher Education, 35(1), 37-60.

Czinkota, M.R. (2006). Academic freedom for all in higher education: The role of the general agreement on trade in services. Journal of World Business, 41(2), 149-160.

Easterby-Smith, M., Crossan, M., \& Nicolini, D. (2000). Organizational learning: Debates past, present and future. Journal of Management Studies, 37(6), 783-796.

Edmondson, A., \& Moingeon, B. (1999). Learning, trust and organizational change. In M. Easterby-Smith, L. Araujo, \& J. Burgoyne (Eds.), Organizational learning and the learning organization (pp. 157-175). London, UK: Sage.

Ewell, P. (1997). Organizing for learning-A new imperative. American Association for Higher Education Bulletin, December, 52-55.

Freeman, I., \& Knight, P. (2004). Hiring criteria of Canadian business schoolsFocus on U.K. PhD graduates. Proceedings of the Administrative Sciences Association of Canada, Quebec, Canada.

Harris, A. (1997). The deprofessionalization and deskilling of teachers. In K. Watson, C. Modgil, \& S. Modgil (Eds.), Teachers, teacher education and training (pp. 57-65). London, UK: Cassell.

Heslin, P. A. (2005). Conceptualizing and evaluating career success. Journal of Organizational Behaviour, 26(2), 113-136.

Hodkinson, P. (1997). Neo-fordism and teacher professionalism. Teacher Development, 1, 69-82.

Hofstede, G. H. (1980). Culture consequences: International differences in workrelated values. London, UK: Sage.

Inkpen, A. C. (1998). Learning and Knowledge Acquisition through International Strategic Alliances. The Academy of Management Executive. 12(4), 69-80. 
Jackson, D. (2010). An international profile of industry-relevant competencies and skill gaps in modern graduates. International Journal of Management Education, 8(3), 29-58.

Kennedy Manzo, K. (2005, April 20). International studies in hard sell in the U.S. Education Week, 24, 1-2.

Knowles, M. (1984). The adult learner: A neglected species. Houston, TX: Gulf.

Kogut, B., \& Singh, H. (1988). The effect of national culture on the choice of entry mode. Journal of International Business Studies, 19(3), 411-432.

Kolb, D. A. (1999). Learning style inventor (Version 3). Boston, MA: McBer.

Kunda, G. (1992). Engineering culture: Control and commitment in a high tech corporation. Philadelphia, PA: Temple University Press.

LaPlaca Cohen (2006). Changes in cultural audiences. Retrieved from http:/ / www. laplacacohen.com/media/company/STUDIES/CtM-Rotterdam2006(eng).pdf

Lei, D., Slocum, J., \& Pitt. R. A. (1997). Building cooperative advantage: Managing strategic alliances to promote organizational learning. Journal of World Business, 32(3), 203-223.

Levinson, N., \& Asahi, M. (1995). Cross national alliances and interorganizational dynamics and learning. Organizational Dynamics, Autumn, 50-83.

Magolda, M. B. B. (1999). Creating contexts for learning and self-authorship: Constructive-developmental pedagogy. Nashville, TN: Vanderbilt University Press.

McAvoy, J., \& Butler, T. (2007). The impact of the Abilene Paradox on doubleloop learning in an agile team. Information and Software Technology, 49(6), 552.

Mitra, D., \& Golder, P. N. (2002). Whose culture matters? Near-market knowledge and its impact on foreign market entry timing. Journal of Marketing Research, 39(3), 350-365

Moore, A. H., Fowler, S. B., \& Watson, C. E. (2007). Active learning and technology: Designing change for faculty, students, and institutions. Educause Review, 42(5), 42.

National Committee of Inquiry into Higher Education. (1997). Higher education in the learning society. Report of the National Committee of Inquiry into Higher Education. Norwich: Her Majesty's Stationery Office.

Nonaka, I. (1996). The knowledge creating company. In K. Starkey (Ed.), How organizations learn (pp. 18-23). London, UK: International Thomson Business Press.

Parkhe, A. (1998). Understanding trust in international alliances. Journal of World Business, 33(3), 219-240.

Paul, M. J. (2003). Double-loop diversity: Applying adult learning theory to the cultivation of diverse educational climates in higher education. Innovative Higher Education, 28(1), 35-47.

Petrigliere, G., \& Petrigliere, J. L. (2010). Identity workspaces: The case of business schools. Academy of Management Learning \& Education, 9(1), 44-60. 
Pink, D. H. (2005). A whole new mind: Why right-brainers will rule the future. New York, NY: Berkeley.

Pun, K. P., Lewis, W. G., \& Chin, K. S. (2003). Design of self-assessment model for evaluating corporate-wide learning performance in manufacturing enterprises. International Journal of Manufacturing Technology and Management, 5(5-6), 428-442.

Purcell, T. W. (1998). Indigenous knowledge and applied anthropology: Questions of definition and direction. Human Organization, 57(3), 258-272.

Ring, P., \& Van de Ven, A. (1994). Developmental processes of cooperative interorganizational relationships. Academy of Management Review, 19(1), 90-118.

Salmador, M. P., \& Bueno, E. (2007). Knowledge creation in strategy-making: Implications for theory and practice. European Journal of Innovation Management, 10(3), 367.

Schwartz, S. H. (1994). Cultural dimensions of values: Towards an understanding of national differences. In U. Kim, H. C. Triandis, C. Kagitcibasi, S. C. Choi, \& G. Yoon (Eds.), Individualism and collectivism: Theoretical and methodological issues. Thousand Oaks, CA: Sage.

Selen, W. (2001). Learning in the new business school setting: A collaborative model. The Learning Organization, 8(3/4), 106.

Senge, P. (1990). The fifth discipline: The art \& practice of the learning organization. New York, NY: Currency Doubleday.

Sooey, J. T. (2010, June 5). Sales and marketing jobs now in demand. Retrieved from http: / / becomealifecoach.amplify.com/2010/06/04/ sales-marketing-jobs-now-indemand

Starkey, K., \& Tempest, S. (2009). The winter of our discontent: The design challenge for business schools. Academy of Management Learning \& Education, 8(4), 576-586.

Tagg, J. (2007). Double-loop learning in higher education. Change, July/August, $35-41$.

Tran, N. M., \& Dawson, B. L. (2008). Reevaluating the concept of diversity management: Considerations for diversity trainers and educators. Academy of Management Learning \& Education, 7(3), 406-417.

Tsang, E. W. K. (1999). A preliminary typology of learning in international strategic alliances. Journal of World Business, 34, 211-229.

Tsang, E. W. K. (2002). Acquiring knowledge by foreign partners from international joint ventures in a transition economy: Learning-by-doing and learning myopia. Strategic Management Journal, 23, 835-854.

Watson, G. H. (2007). Change management: How important is it for six sigma? ASQ Six Sigma Forum Magazine, 6(4), 39-40.

Wilkinson, I. F., \& Young, L. C. (2005). Toward a normative theory of normative marketing theory. Marketing Theory, 5(4), 363-396. 
Williams, R. (1980). Problems in materialism and culture. London, UK: Verso.

Williams, S. (2007). A supplier development programme: The SME experience. Journal of Small Business and Enterprise Development, 14(1), 93.

Yeo, R. K. (2007). Problem-based learning: A viable approach in leadership development? Journal of Management Development, 26(9), 874.

Yorke, M. (2000). Developing a quality culture in higher education. Tertiary Education and Management, 6(1), 19-36.

\section{CONTACT INFORMATION}

Ina Freeman

Associate Professor

Jones International University

9697 East Mineral Avenue

Centennial, CO 80112 USA

ina.freeman@gmail.com

Ina Freeman is currently working in the community and teaching as an Adjunct Associate Professor at Jones International University. Her research interests include marketing in the international marketplace, CSR, and international marketing education.

Peter Knight has been Assistant Professor of Marketing at the University of Wisconsin Parkside since 2007 and also has taught at Canadian universities such as Laurentian, Carleton, and UOIT. His research interests are in marketing and eCommerce program evaluation as well as cross-cultural and virtual learning. 